\title{
No Small-talk in paradise: Why Elysium fails the Bechdel Test, and why we should care
}

\section{Christa van Raalte}

Introduction: why we need to keep women on the agenda

Discussions of women in film are always about a great deal more than they may appear to be at first sight. Feminist film theory, which Sue Thornham characterises as "the exploration of the complex triangular relationship between 'Woman' as a cinematic representation, women as historically and culturally positioned subjects, and the feminist theorist, who speaks.... as a woman" (1997:171), has made a significant contribution to the development of feminist theory, and thus, by extension to the political project of feminism. For while the relationship between representations of women in movies and the status and opportunities of women in the real world is not straightforward, neither is it insignificant. After a century of feminist activism, women are still marginalized in many areas of human activity throughout the Western world - and women are still marginalized in the outputs of the culturally powerful dream factory that is the Hollywood film industry. One need not look for a simplistic causal relationship between these two facts to infer that this is not a coincidence.

In 1974, Molly Haskell observed that the image of woman in film functions predominantly as "the projection of male values", "the vehicle of male fantasies" or "the scapegoat of male fears" (1987: 39). For all its limitations, she speculates that the despised 'woman's film' offers the female filmgoer a degree of "compensation for all the male-dominated universes from which she has been excluded: the gangster film, the western, the war film, the policier, the rodeo film, the adventure film" (1987: p155). Forty years on, Hollywood has evolved a new range of gender representations, inhabiting new and re-versioned movie genres, in dialogue with new cultural sensitivities and anxieties, and new technological and economic contexts. Nevertheless, the representation of women in mainstream film remains problematic both in qualitative terms (women are not to be found in $51 \%$ of key dramatic roles - or even $51 \%$ of speaking roles - across the range of mainstream releases) - and in qualitative terms (women still fulfil relatively narrow range of roles and narrative functions and are still largely defined in terms of their relationship to men). The modern 'chick flick' continues to offer a degree of 'compensation' for the marginalisation, or even complete absence of women in a range male-dominated movie universes. Despite the box office success enjoyed by some 
recent female-led action films, these exceptions - however notable, remain just that: exceptions that effectively prove the gendered rule.

Meanwhile feminist film theory has also evolved, developing a complex, highly nuanced and sometimes conflicting set of understandings about how Woman operates as a textual sign, how women respond as audiences and how either relates to an immediate industrial or wider social context. Film, however, continues to engage feminists as a reflection of cultural values and ideology - both explicit and implicit, as a contributory factor within culture and ideology with the power to shape perceptions and understanding, as a conceptual laboratory within which to explore notions of agency, identity and desire, and as a battleground where different theoretical approaches and ideological positions lock horns.

In this chapter I will examine some of these concerns through the prism of the Bechdel Test, a cultural meme that has recently gained some currency in the popular press and attracted some opprobrium from film critics. I will apply the 'test' to the sci-fi blockbuster Elysium (Blomkamp, 2013), arguing that the utilisation of the film's two female leads, and the pointed manner in which they are deprived of an opportunity to pass the Bechdel Test, bring into focus some critical concerns about the continued marginalisation of women in twenty-first century Hollywood film.

\section{The Bechdel Test: why a thirty year old joke still matters}

The Bechdel Test started life as a joke in cartoonist Alison Bechdel's comic strip, 'Dykes To Watch Out For'. It was the subject of a 1985 episode entitled 'The Rule' in which a woman tells her friend that for her to watch a film it has to meet three conditions. It has to have (1) at least two women in it, (2) who talk to each other, (3) about something besides a man. This, it is implied, excludes the majority of movies to be found playing in a mainstream cinema. (Bechdel, 2005). ${ }^{\text {i }}$ The test has gained currency among feminists over the intervening years and has been somewhat refined along the way to maintain the spirit of the original, such that many commentators look for two named women, and more recently stipulate that they should talk for more than sixty seconds. (Sarkeesian, 2012) Gathering momentum after the turn of the current century, largely due to the proliferation of alternative film and culture blogs, it seems to have crossed over into mainstream discourse around 2010/11 with its usage (by male critics) in Entertainment Weekly and The New Yorker (Harris 2010; Friend 2011) 
The significance of the Bechdel Test becomes apparent on visiting the various fan sites that feature lists of films that do or don't pass the test. Putting aside various long-running debates about disputed examples, this material points to a clear sense that those films that are taken seriously (by critics, financiers and fans alike) overwhelmingly depict the male-dominated universes identified by Haskell... and that those universes do continue to be male dominated for the most part. The sceptic is advised to engage in a simple thought experiment: to draw up a list of films that would fail the reverse-Bechdel Test. It is surprisingly difficult to identify Hollywood films, of any genre, that fail to offer (1) at least two named men (2) who talk to each other, (3) about something other than a woman. This reverse-test serves to underline the extent of the discrepancy and thus the degree to which women, women's concerns and women's voices are indeed marginalized across the outputs of the mainstream industry. ${ }^{\text {ii }}$

The Bechdel Test in contemporary commentary: popular interest and critical objections

In the spring of 2013 Stacy Smith and her team at the Annenburg School for Communication, University of Southern California published the latest in a series of reports on gender imbalance in the feature film. They analysed the 100 highest grossing films, at US box-offices, for the past 5 years and found that less than a third of speaking characters were female. For 2012, in fact, the figure was $28.4 \%$, down from an unedifying high of $32.8 \%$ in 2009 (Stacy et al 2013). Smith's report attracted a considerable amount of media coverage - both in the blogosphere and in the traditional media - which in turn seemed to reawaken popular interest in "The Bechdel Test" - an attractive motif for journalists, since it expresses with laudable economy many of the concerns addressed in Smith's study.

Both fans and popular film critics made the connection between Smith's study and the summer blockbuster Pacific Rim, with one fan proposing an alternative 'Mako Mori' test, focusing on narrative arc rather than interaction. (Romano 2013) Then in October, four Swedish independent cinemas and one cable network, supported by the Swedish Film Institute, announced that they would be applying an 'A' rating to films, based on the Bechdel Test. (Associated Press 2013). This gave rise, as might be expected, to some impassioned responses from the test's detractors. (Kolvunen et al., 2013)

Since the publication of the Annenberg report, the Swedish rating exercise and the associated media debate, the Bechdel Test has been used (and misused) with increasing frequency on popular film sites, in the mainstream press and in commentaries on a diverse range of cultural phenomena including television drama, music videos, games, social media and even WWE 
wrestling ${ }^{\mathrm{iii}}$. A term that has gained such widespread usage clearly speaks to a phenomenon in need of naming, and as such is worthy of serious academic attention notwithstanding (or possibly because of) its origins in popular culture. Indeed it is beginning to be utilized in academic writing $^{\text {iv }}$, although largely in contexts other than that of mainstream, Hollywood film for adult audiences - the context in which it was coined.

Nevertheless, the test induces very mixed reactions and not a little discomfort among serious cultural commentators. As Charlie Jane Anders remarks in the blog io9, "The Bechdel Test has become a huge part of our conversation about pop culture, but we all feel compelled to dismiss it or minimize it" (Anders, 2014), and indeed male film critics and feminist writers alike have been inclined to dismiss the test as simplistic, reductive, or irrelevant. Mallory Andrews, for example, writing in the film blog Indiewire, takes issue with the test on the grounds that "Passing [it].... does not a female-positive film make." (Andrews, 2014), while Robbie Collins opines, in the Telegraph, that "it fosters a way of thinking about films that has almost nothing to do with cinema." (Collins, 2013)

The objections are, almost exclusively, predicated on the things the test is not. It is not a measure of film quality: Apocalypse Now would not pass, nor would The Good, the Bad and the Ugly, Citizen Kane or (notably) Run, Lola, Run... in fact, pick any title from the usual popular lists of greatest films and the chances are it will fail the Bechdel Test. Neither can it be used to determine the feminist credentials of a film: Mean Girls would pass, as would any number of cheerleader films, Carry On films and Katharine Cookson dramatizations. Despite its almost exclusive focus on heterosexual relationships, Sex in the City also passes the test: they talk about shoes, after all.

However the Bechdel Test does effectively highlight the extent to which women are consistently marginalised across mainstream film, both in terms of the number of speaking roles and the extent to which female characters are predominantly defined in terms of their relationships with men. Its simplicity, I would argue is a point in its favour, making it immune to the kind of post-modern sophistry that might otherwise serve to obscure some unpalatable truths about modern culture and the society that produces and consumes it. And while it does not grapple with qualitative issues of ideology and representation it does have the virtue of being relatively objective. It is its simplicity and clarity that makes is so appealing to popular commentators like Aja Romano, for whom it is "hitherto unrivaled for its basic stark 
illustration of how difficult it is to find movies that feature women as characters independent from male storylines" (Romano, 2013). The same simplicity endows it with considerable rhetorical power, as Mark Harris remarks: "The wonderful and tragic thing about the Bechdel Test is not.... That so few Hollywood films manage to pass, but that the standard it creates is so pathetically minimal." (2010). This simplicity is deceptive, however. The specific criteria of the test actually speak to key theoretical issues with regard to the representation of women in film, which helps to explain why these apparently 'minimal' standards prove so challenging for mainstream film.

\section{A joke to take seriously: the Bechdel Test as a critical tool}

The first criterion of the test concerns a minimum number of women. As Smith's study clearly demonstrates, there is an issue with the representation of women in film in a purely statistical sense. The $30 \%$ of speaking characters that are female do not constitute a proportionate sample $\mathrm{o}$ the population, and when a population is under-represented in this sense within media texts, the burden of representation placed upon each character is always problematic. The problem is exacerbated, moreover, in the case of the single female lead since, as Claire Johnston (1973) and successive feminist critics have compellingly argued, within a classical narrative structure she will invariably be required to fulfill the role of "Woman", a mythical creation having little to do with actual women and everything to do with defining masculinity. Multiple female characters undercut this, and open up the possibility of a broader understanding of what it might mean to be a woman. The fact that the test takes no account of the narrative prominence of female characters, and fails female led action films such as Salt (2010) is not an oversight but a key element of the perspective it brings.

The requirement for the two characters to talk - as opposed to simply share a scene, or take part in some form of physical interaction - is particularly interesting. Women's voices have been problematised throughout history and throughout culture. Kaja Silverman in The Acoustic Mirror (1998) notes the various ways in which women's speech is repressed, silenced, rendered unreliable or damaging, or emptied of authority in film narratives. Moreover conversation between women raises the possibility of a relationship between them as independent human beings, without reference to a male character. In a similar vein, the stipulation that the conversation should be about something other than a man serves to highlight the prevalence of female characters whose narrative roles are defined entirely in 
terms of the male characters in a film. In practice films that pass this requirement with flying colours tend to be, themselves, about something other than a man.

This is not to say that such films will be 'feminist' texts - indeed the feminist potential of film discourse is always contested and never straight forward, not least due to the practice of 'reading against the grain' that is central to so much feminist writing on film. Arguably any relationship or conversation between women, however, that is not male orientated, opens up spaces within the text to explore questions and concerns that are frequently marginalised, raising the possibility, however tentatively, of a discourse and a narrative that is not entirely phallocentric.

The activists responsible for persuading Swedish exhibitors to adopt the 'A' certificate focus on just this point when challenging their detractors: "Instead of rejecting the Bechdel test and the A rating as simplistic, critics should focus on the obvious. What does it mean that, in film, women can barely be imagined to have important things to say to each other?" (Kolvunen et al., 2013). They go on to analyse some of the negative responses they received to their initiative, which betray some disturbing underlying attitudes such as those of the critic who suggested that the test is of no significance since many pornographic films would pass it. Apart from questioning the veracity of this claim, Kolvunen and her collaborators suggest it might be "relevant to consider why pornography comes to these critics' minds when imagining scenarios in which women talk to each other." [ibid] The implication is that a foundation of straight-forward misogyny lies beneath the veneer of sophisticated cultural commentary and film criticism.

Of course misogyny, like racism, is no longer a socially acceptable discourse in the West: 2013 saw a number of high profile cases of public figures reprimanded or sacked for making sexist or misogynistic statements which, a few decades earlier, would have passed without comment. However the evidence suggests that misogyny, like racism, has not been eliminated from our equality-conscious public discourse so much as repressed. It continues to bubble away beneath the surface of the culture, breaking through from time to time in a quite disturbing way, particularly in the anonymous and uncensored context of 'social' media. Trolling is generally misogynistic, with online abuse particularly virulent against women who have the audacity to speak out against overt or covert sexism (BBC, 2013). Among some of the more high profile recent cases were those of Laura Bates, convener of the Everyday Sexism Project, and Caroline Cirado-Perez, who campaigned for Jane Austen to be represented on a British bank note. Arguably more significant than these individual instances 
is the regularity with which 'everyday sexism' online is implicitly or explicitly focused on silencing women's speech. The misogynistic material that caused a group of activists to challenge Facebook's take-down policies in May 2013 was dominated by text and images extolling the silencing of women's speech. (Altavena, 2014)

\section{The Bechdel Test and the Blockbuster : marginalising women in Elysium}

While social media and the self-generated texts that populate so many online platforms play an increasingly key role in popular culture, however, I would argue that mainstream texts, and Hollywood film in particular, are still important in terms of how they reflect and inform that culture. With its powerful 'phatic' properties and near universal reach, Hollywood continues to have the capacity to validate and reinforce ideological positions - and by the same token to manifest in its imagery and memes the return of social repressed. Hence my focus in this paper on a film which would not usually be on the radar of a feminist film theorist.

Neill Blomkamp's Elysium is unquestionably a mainstream Hollywood film, a sci-fi action movie made primarily to target the profitable 15-25 year old male audience while striving to incorporate a broader appeal. As a science-fiction film it has the potential to explore complex social and philosophical issues, and indeed, like the director's previous film, District 9, it addresses questions of social equality.... but notably not in relation to gender. As an action film it is generically predisposed to minimize engagement with such issues in favour of highoctane action and special effects.

In the dystopian future of the film, earth is a post-apocalyptic slum, with a primarily Latino and black population, while the predominantly white upper class live apart in the artificial satellite world of Elysium. The denizens of Elysium benefit, among other things, from a technology that is able to cure all disease and injury - a technology not available to the citizens of earth. Matt Damon stars as Max, the inexplicably white hero, who finds himself on a mission to break Elysium's security codes while Alice Braga plays his love interest, Frey, whose terminally sick child can only be cured by Elysium's technology. Jodie Foster shares star billing as the chief villain of the piece, Delacourt, the head of security for Elysium, who is charged with preventing the illegal immigration of desperate earth dwellers. Blomkamp's long time collaborator, the South African actor Sharlto Copley gives by far the best performance in the film as Delacourt's violent and sadistic henchman, Kruger. Given the film's genre, and its focus on violent action sequences, a filmgoer encountering the marketing campaign would not expect Elysium it to pass the Bechdel Test, yet it very nearly does. And it 
is the nature of the 'near miss' -the precise mechanics of its failure - that is particularly telling in terms of Hollywood's representation of women.

Despite a predominantly male cast, Elysium does feature the requisite two named female characters, each of whom occupies a considerable amount of screen time and plays a critical role within the narrative. Braga's character, Frey, is a patchwork of stereotypes: she is Max's childhood sweetheart, and better angel, as well as a nurse, and a mother; she is also a victim a damsel in distress inevitably captured by the evil Kruger as 'bait' to lure Max to his doom and finally a survivor, living to usher in a better future. Frey offers little of interest to the feminist critic, except perhaps to note the narrative multi-tasking she is expected to perform (not atypically as a female character) in terms of activating and/ or embodying diverse plot devices, whereas most of the numerous cast of secondary male characters are required to perform just one narrative function apiece.

Delacourt, is an altogether more interesting character: cool, clever and thoroughly villainous, both as the representative of Elysium's elite, and as the leader of a plot to oust more moderate elements among its government in a cyber-coup. Yet she is, as a number of reviewers have remarked, inexplicably killed off before the end of the film, with the role of chief villain taken over by her henchman - inexplicably, that is, unless one takes her gender into account: in the world of Hollywood female villains primarily fight only female heroes - and Elysium does not feature one of these. However it is less the timing than the manner of her death that is key to the current discussion.

In the penultimate act of the film Max, his rebel allies, Freya and her daughter have all arrived on Elysium. Kruger and his crew have failed in what was intended to be something of a stealth mission to stop the rebels: not only have the latter made it past Elysium's defences, but Kruger's heavy handed tactics have alarmed Elysium's citizenry. Kruger himself has been horribly injured in the process, but has been restored and physically enhanced using the advanced medical technology. Freya and her child have been captured and locked in a storage area.

Kruger, infuriated by his failure, and presumably his injury, stands at a sink, stripped to the waist and looking in the mirror at his reconstructed face and reinforced body. Delacourt walks into the room haranguing him for "crashing an unlicensed vehicle" and potentially betraying their treasonous plot to the administration. Kruger, by way of response, punches and smashes the mirror in front of him then, as Delacourt reminds him that they could both be hanged if discovered, he turns from the sink, holding a shard of glass, and stabs her in the neck. His 
underling meanwhile goes about his business, quietly smiling his approval. Kruger drags Delacourt across the room and locks her in the storage area with Frey, who tries in vain to staunch Delacourt's wound. Eventually Delacourt waves her away, and dies - although, of course, she never speaks.

\section{$\underline{\text { No small-talk in paradise: limiting women's speech }}$}

One of most striking things about this sequence is the degree to which Delacourt's behavior is out of character. She is written and played, up to this point, as every inch the cool professional: economical and to the point in her dialogue, icy in her self- control, and well aware that Kruger, is a dangerous psychopath who must be handled with care. Yet in this scene her tone, not to mention her repetitive statement of the obvious, could be said to amount to 'nagging' - and indeed the scene at the sink resembles nothing so much as the stereotypical image of a wife 'nagging' her husband as he stands at the shaving mirror. Indeed neither sink nor mirror seem to have much purpose other than to create this image. The unsettling smile of the other man in the background, who does not so much as finch when Kruger kills Delacourt, reinforces the sense of an explicitly gendered attack. Such a very odd moment, so much out of step with the preceding narrative in terms of characterisation and relationship dynamics is surely only explicable in terms of a fundamental misogyny breaking through the surface of textual versimilitude - in effect the return of the social repressed.

This reading is the more compelling due to the manner in which Kruger kills Delacourt. To cut her throat - rather than to stab her in the gut, for example, as would be a more common mode of attack in this sort of film - seems pointed to say the least. For Delacourt's power is exercised entirely in the form of speech. She does not engage in physical combat, or personally hack data: she commands these actions in others. Her voice is her weapon, recognised by humans and programmable machines alike. The immediate effect of Kruger's attack is to silence her and thus to disempower her entirely. It also, of course, prevents any dialogue between her and Frey as they are held captive together. They interact a little, but they do not talk.

This is a pity, because in a parallel universe - one in which women's talk is considered a fit subject for mainstream film - Frey and Delacourt would have a great deal to discuss, without once mentioning a man. Frey has a child who can only survive in a world where access to services and technology is more equally distributed, while Delacourt (also explicitly designated a mother in the original script, although her status in this respect is less clear in the 
final cut of the film) has argued the case for limiting such access specifically in terms of protecting the children of Elysium's elite. The two women are intimately concerned with debates around the future of humanity, and so better placed than anyone to discuss the philosophical and practical implications of the film's dystopian vision.

\section{Conclusion: resignation or resistance?}

But, of course, Elysium is not really that kind of movie, and its focus in the final act is on the male hero and his remaining, male, opponent - both supplementing their masculine prowess with cybernetic exoskeletons in order to create spectacular fight scenes. The women, having fulfilled their respective structural functions within the narrative, are relegated to the margins, as we have come to expect. Indeed so unremarkable is the film, in this respect, that it could be considered a waste of energy to object. This is a sentiment echoed by Bechdel herself in response to the media debates last year:

"I'm glad I just can't seem to rise to the occasion of talking about this fundamental principle over and over again, as if it's somehow new, or open to debate. Fortunately, a younger generation of women is taking up the tiresome chore.” (Bechdel 2013)

It is precisely the unremarkability of the way in which a film such as Elysium represents and utilises female characters, however, that makes it worthy of remark. As Bechdel says, the marginalisation of women in film has become, frankly, boring. It has been discussed until there seems to be nothing left to say, and feminists leave the fray battle-weary and demotivated - and yet it persists. Which perhaps explains why a tongue-in-cheek set of rules, a joke made for a very niche audience nearly 30 years ago, has managed to survive in the hinterland of popular culture - and why, despite its limitations, it is still capable of eliciting passionate responses on both sides.

Elysium is not a very good film, for all kinds of reasons that have nothing to do with the way it marginalises women, so why should we care whether it 'passes' the Bechdel test? I want to suggest that, in the great scheme of things, it does, actually, matter.

\section{Bibliography}

Altavena, L (30 ${ }^{\text {th }}$ May 2013) 'Why misogyny blew up on facebook - and what's next.' Kicker [Online] Available at http://gokicker.com/2013/05/30/why-misogyny-blew-up-on-facebookand-whats-next/ [Accessed 19/09/14] 
Anders, C.J. (6th April 2014) 'Why the Bechdel Test is More Important than you Realize', io9 [Online] Available at http://io9.com/why-the-bechdel-test-is-more-important-than-you-realize1586135613. [Accessed 27/08/14]

Andrews, M. (19 ${ }^{\text {th }}$ August 2014) 'Clouds of Sils Maria' and 'Cure: The Life of Another' Reveal Where the Bechdel Test Comes Up Short', Indiewire [Online] Available at http://blogs.indiewire.com/criticwire/clouds-of-sils-maria-and-cure-the-life-another-revealwhere-the-bechdel-comes-up-short-20140819. [Accessed 27/08/14]

Associated Press in Stockholm (6 $6^{\text {th }}$ Nov 2013) 'Swedish cinemas take aim at gender bias with Bechdel test rating, The Guardian [Online] Available at http://www.theguardian.com/world/2013/nov/06/swedish-cinemas-bechdel-test-films-genderbias. [Accessed 27/08/14]

BBC $\left(29^{\text {th }}\right.$ July 2013) 'Twitter abuse: Why cyberbullies are targeting women', BBC News [Online] Available at http://www.bbc.co.uk/news/technology-23488550. [Accessed 19/09/14]

Bechdel, A (16 ${ }^{\text {th }}$ August, 2005) 'The Rule', Dykes to Watch Out For [Online] Available at http://dykestowatchoutfor.com/the-rule [Accessed 27/08/14]

Bechdel, A ( $8^{\text {th }}$ Nov 2013) 'Testy', Dykes to Watch Out For [Online] Available at http://dykestowatchoutfor.com/testy [Accessed 27/08/14]

Collins, R. (15 ${ }^{\text {th }}$ Nov 2013) 'Bechdel Test is damaging to the away we think about film", The Telegraph [Online] Available at http://www.telegraph.co.uk/culture/film/10450463/Bechdeltest-is-damaging-to-the-way-we-think-about-film.html [Accessed 27/08/14]

Dyer, R. (1993) The Matter of Images: Essays on Representations. London: Routledge.

Friend, T. (11 ${ }^{\text {th }}$ April 2011) 'Funny Like a Guy: Ana Faris and Hollywood's Woman Problem', The New Yorker [Online] Available at http://www.newyorker.com/magazine/2011/04/11/funny-like-a-guy. [Accessed 03/09/14]

Haskell, M. [1974] (1987) From Reverence to Rape: The Treatment of Women in the Movies. ( $2^{\text {nd }}$ Edition) Chicago: University of Chicago Press

Harris, M. (6 ${ }^{\text {th }}$ August 2010) 'I am Woman. Hear Me.... Please!', Entertainment Weekly [Online] Available at http://www.ew.com/ew/article/0,,20408121,00.html. [Accessed 27/08/14]

Johnston, C. (1973) “Woman's Cinema as Counter- Cinema" in Notes on Women's Cinema, London: SEFT.

Koivunen, A., Ryberg, I. and Horak, L. (27 ${ }^{\text {th }}$ Nov 2013). 'Swedish cinema's use of the Bechdel test is a provocation that works', The Guardian [Online] Available at http://www.theguardian.com/commentisfree/2013/nov/27/swedish-cinema-bechdel-test-works. [Accessed 27/08/14]

Romano, A. (18 ${ }^{\text {th }}$ August 2013) 'The Mako Mori Test: Pacific Rim inspires a Bechdel Test alternative', The Daily Dot [Online] Available at http://www.dailydot.com/fandom/makomori-test-bechdel-pacific-rim/. [Accessed 27/08/14]

Sarkeesian, A. (15 ${ }^{\text {th }}$ February 2012) 'The Oscars and the Bechdel Test', Feminist Frequency [Online] Available at http://www.feministfrequency.com/2012/02/the-2012-oscars-and-thebechdel-test/ [Accessed 03/09/14] 
Silverman, K. (1988) The Acoustic Mirror: the Female Voice in Psychoanalysis and Cinema. Bloomington \& Indianapolis: Indiana University Press.

Smith, S.L., Choueiti, M., Scofield, E., and Pieper, K., (2013) Gender Inequality in 500 Popular Films: Examining On-Screen Portrayals and Behind-the-Scenes Employment Patterns in Motion Pictures Released between 2007-2012. [Online] Available at http://annenberg.usc.edu/Faculty/Communication\%20and\%20Journalism/SmithS.aspx [Accessed 27/8/14]

Thornham, S. (1997) Passionate Detachments: An Introduction to Feminist Film Theory. London \& New York: Arnold/ OUP.

Filmography

Apocalypse Now (Francis Ford Coppola, 1979). Zoetrope Studios.

Citizen Kane (Orson Welles, 1941). RKO Radio Pictures

District 9 (Neill Blomkamp, 2009). Tristar Pictures

Elysium (Neill Blomkamp, 2013). Tristar Pictures

Mean Girls (Mark Waters, 2004). Paramount Pictrues

Pacific Rim (Guillermo del Toro, 2013). Produced for Warner Bros.

Run, Lola, Run (Tom Tykwer, 1998). X-Filme Creative Pool

Sex in the City (Michael Patrick King, 2008). New Line Cinema

Salt (Phillip Noyce, 2010). Columbia Pictures

The Good, the Bad and the Ugly (Sergio Leone 1966). PEA

Notes

${ }^{i}$ Bechdel herself attributes the idea to her friend Liz Wallace (immortalized on the cinema marquee in the first frame of the comic strip) - but points out that the origins are in Virginia Woolf's A Room of My Own - in particular the passage that begins "Chloe Likes Olivia" - which addresses similar issues in literature. (Bechdel 2013)

ii There has been some discussion with regard to the immediate and interconnected industrial causes behind this discrepancy: the dominance of male film-makers, taught conventions of script-writing, audience expectations and attitudes. None of these, of course, exist in isolation from a broader social context; on the contrary they can be said to offer an interesting metonym for that broader context. This discussion, however, is beyond the scope of the current chapter. 
iii A few recent examples below give a sense of the extent to which the term has entered the mainstream vocabulary [All accessed 27/08/14]

on film:

- http://www.dailydot.com/opinion/guardians-of-the-galaxy-fails-women/

- http://www.spectator.co.uk/arts/cinema/9286962/the-inbetweeners-now-hasto-out-inbetweeners-itself/

on television:

- http://community.ew.com/2014/08/15/alias-react-a-broken-heart/

- http://www.independent.co.uk/arts-entertainment/tv/features/doctor-whoreturns-new-doctor-new-direction-right-9656996.html

on music:

- http://www.slate.com/articles/arts/the_music_club/features/2011/music_club_ 2011/best_music_2011_how_about_a_bechdel_test_for_albums_by_male_rappers_. html

- http://jezebel.com/5797747/the-willis-test-is-the-new-bechdel-test

on games:

- http://gameological.com/2012/07/something-other-than-a-man-15-games-thatpass-the-bechdel-test/

on social media

- http://www.sciencedaily.com/releases/2014/04/140423102748.htm

on wrestling

- http://www.cagesideseats.com/2014/8/15/6004623/wwe-fan-female-abyssstephanie-mcmahon-brie-bella-raw-summerslam-2014

iv Examples of recent academic usages of the Bechdel Test are listed below [All accessed 27/08/14]

- Garcia, D., Weber, I. and Garimella, V.R.K, (2014) 'Gender Asymmetries in Reality and Fiction: The Bechdel Test of Social Media', in the Proceedings of the Eighth International AAAI Conference on Weblogs and Social Media [Online]. Available at http://www.aaai.org/ocs/index.php/ICWSM/ICWSM14/paper/view/8070.

- Law, M. (2014) 'Sisters doin'it for themselves: Frozen and the evolution of the Disney heroine', in Screen Education, Issue 74 [Online] Available at http://www.metromagazine.com.au/screen_ed/.

- Tešija, J., Car, V. and Šipić, J. (2014) 'The analysis of female characters in the Pula Film Festival award-winning films 1992-2011' in Young Women in Post-Yugoslav Societies: Research, Practice and Policy, Adamović, M., Galić, B., Gvozdanović, A., Maskalan, A., Potočnik, D. and Somun Krupalija, D. (Eds), Sarajevo: Institute for Social Research and the Center for Human Rights, University of Sarajevo. 
- Lawrence, F.K., (2011) 'SPARQLing Conversation: Automating The Bechdel-Wallace Test', published in the proceedings of the ACM Hypertaext Conference [Online] Available at http://nht.ecs.soton.ac.uk/2011/papers/12-flawrence.pdf . 